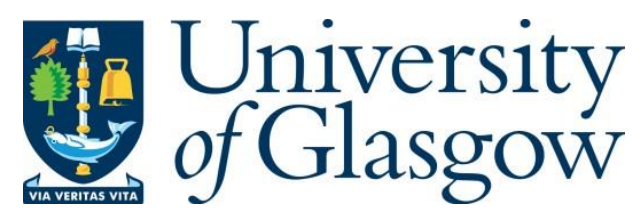

Kelp, C. (2013) A practical explication of the knowledge rule of informative speech acts. European Journal of Philosophy, 21(3), pp. 367-383.

There may be differences between this version and the published version. You are advised to consult the publisher's version if you wish to cite from it.

http://eprints.gla.ac.uk/140954/

Deposited on: 16 May 2017

Enlighten - Research publications by members of the University of Glasgow http://eprints.gla.ac.uk 


\title{
A Practical Explication of the Knowledge Rule of Informative Speech Acts
}

\author{
Christoph Kelp*
}

\begin{abstract}
This paper defends the knowledge rule of informative speech acts. It is argued that Edward Craig's insightful practical explication of the concept of knowledge can be extended to motivate the knowledge rule. A number of problem cases for the knowledge rule are addressed and accommodated.
\end{abstract}

\section{Introduction}

A thesis that has enjoyed increasing popularity in recent years is the socalled knowledge rule of assertion:

KRA One must: assert $P$ only if one knows $P{ }^{1}$

There are a variety of by now well-known phenomena that have been cited in support of KRA. ${ }^{2}$ Most notably, defenders of KRA point to the fact that assertions of the following kinds of proposition are inappropriate:

LP Ticket $x$ won't win fair lottery $l$

MP $P$ but I don't know that $P$

Defenders of KRA have often pointed out that, while rival accounts struggle to provide a satisfactory explanation of the inappropriateness of assertions of lottery and Moorean propositions (respectively, LP and MP above), KRA has a simple and elegant explanation ready at hand. One

*Institute of Philosophy, University of Leuven, Dekenstr. 2, \#3220, B-3000 Leuven, Email: christoph.kelp@hiw.kuleuven.be 
cannot know these propositions. Assertions of them are thus bound to violate KRA. In this way their inappropriateness can be explained. Besides the inappropriateness of assertions of Moorean and lottery propositions, defenders of KRA have argued that the knowledge rule is supported by conversational patterns. Assertions can typically be challenged by questions of the form "How do you know?" and do not remain in good standing if the challenge cannot be met.

Consider next the class of informative speech acts which includes, among others, acts of telling, disclosing, revealing and testifying. Generally speaking, I will take an informative speech act to be a speech act the point of which consists in engendering outright, true belief in the hearer ${ }^{3}$, which has a word-to-world direction of fit and in which the speaker expresses the attitude of belief. ${ }^{4}$ The arguments for KRA presented above, if successful, can be adapted to provide support for the parallel knowledge rule of informative speech acts (henceforth also "KRI" or "the knowledge rule" for short). ${ }^{5}$ To see this, notice that informative speech acts to the effect that Moorean or lottery propositions are true are just as inappropriate as the corresponding assertions. I cannot with propriety disclose to you, for instance, that I am currently sitting at my desk but don't know this to be the case. And if I were to tell you that your ticket will lose the lottery, my speech act would also be bound to be inappropriate. Finally, it can be argued that the relevant conversational patterns also confirm KRI. Informative speech act can also be challenged by asking how the speaker knows. If the challenge cannot be met, the speech act will not remain in good standing. ${ }^{6}$

These phenomena provide what many would consider to be strong support for the knowledge rule. The aim of this paper is to bolster the case for KRI. In order to do so I will first argue that Edward Craig's insightful practical explication of the concept of knowledge can be extended to motivate the knowledge rule. ${ }^{7}$ Second, I will discuss a number of cases that may appear to disconfirm the knowledge rule and show that they pose no threat to the version of the knowledge rule defended here.

\section{Craig's practical explication of the concept of knowledge}

In his 1990 book Knowledge and the State of Nature, Craig sets out to provide a practical explication of the concept of knowledge. That is to say, he aims to illuminate the concept of knowledge by explaining how we came to have it in the first place. Craig's project breaks down into two parts. In the first part, he devises a hypothesis about the sorts of needs that pressurised our "ancestors" 8 to introduce an ancestor of our concept of 
knowledge-a concept of protoknowledge, as Kusch [Kus09] has aptly labelled it-and develops the conditions governing its application. In the second part, Craig describes how the ancestor concept evolved into the concept of knowledge we have today. In the next section I will argue that Craig's practical explication can be extended to motivate the knowledge rule of informative speech acts. In order to be able to do this, however, it will be necessary to first look in more detail at Craig's own project.

Craig first points out that our ancestors need true beliefs about the environment and they can get them either through their "on-board sources" or, alternatively, from other agents in the community, i.e. from informants. He then observes that, as a result, our ancestors also need concepts to evaluate informants. His crucial hypothesis is that the ancestor of our concept of knowledge was introduced in response to this need: its function is to flag good informants.

In order to develop the conditions governing the application of the ancestor concept, Craig invites us to imagine an ancestor inquirer, who does not yet have a belief about $P$ but wants to acquire one from a prospective informant. Let INQ be any ancestor filling the role of inquirer and INF be any other ancestor occupying the role of informant. Craig now asks what general properties INQ will want INF to have. These properties will by the same token be general properties of the good informant. Since, according to his hypothesis, it is the very job of the concept of protoknowledge to flag good informants, reflection on the general properties of the good informant will allow us to glean insight into the application conditions of the concept of protoknowledge: the latter concept will be applicable only to subjects that have the former properties.

Craig proposes a number of general properties that, in the situation under consideration, INQ will want INF, to have. INQ will want INF to be such that

PK-1 either $P$ and INF tells INQ that $P$ or not- $P$ and INF tells INQ that not- $P$;

PK-2 if INF tells INQ that $P$, INQ shall thereupon believe that $P$;

PK-3 INF is as likely to be right about $P$ as INQ's concerns require;

PK-4 INF is detectable by INQ as likely (enough) to be right about $P$;

PK-5 the channels of communication are open between INF and INQ;

PK-6 INF is accessible to INQ here and now. [Cra90, 12-13, 85] 
While, as Craig argues, the concept of protoknowledge so construed approximates our concept of knowledge, there remain differences between the two. For there are a number of cases in which agents intuitively fall under the concept of knowledge but not under the concept of protoknowledge. To take one of Craig's [Cra90, 82] own examples, suppose Luigi has seen where the body is buried but he won't tell. Intuitively, Luigi knows where the body is but the channels of communication aren't open between him and us so that he isn't a protoknower.

In the second part of his project, Craig explains away these differences by telling a story about how the concept of protoknowledge evolved into the concept of knowledge we are familiar with today. Crucial in this part of the story is the idea of objectivisation of a concept. There are a number of subjective elements in the conditions governing the application of the above concept of protoknowledge: whether INF is as likely to be right as INQ's concerns require depends on INQ's concerns; whether she is detectable by INQ as likely (enough) to be right depends on INQ's cognitive capacities; whether she is accessible to INQ depends on INQ's location and his available methods of communication; whether the channels of communication are open between INQ and INF depends on what languages the two speak, whether INQ is the kind of person to whom INF would divulge the information at issue and so on. It can easily be seen that whether INF satisfies these conditions may vary depending on who fills the role of inquirer. In this way, then, conditions governing the application of concept of protoknowledge contain subjective elements.

Now, Craig points out that in more complex communities of agents it will be extremely useful to distinguish between subjective and objective conceptions of certain phenomena including the one of the good informant. To see this, consider a situation in which INQ does not have the abilities requisite to detect INF as likely to have the right answer to the question that is bothering him. Suppose, at the same time, that INQ is part of a community that has detective agents who have the relevant abilities INQ lacks. Let DET be any agent who fills the detective role. Suppose, furthermore, the channels of communication aren't open between INQ and INF, but, in INQ'S community, there are interpreters who can communicate with INF (as well as with INQ). Let INT be any agent occupying the interpreter role. Finally, suppose INF will never be anywhere near INQ. In this situation, INF isn't a good informant in the subjective sense. After all, INF doesn't satisfy PK-4 to PK-6 (henceforth also "epistemic accessibility conditions", for obvious reasons). At the same time, suppose that the agents in the community under consideration can collaborate to achieve their goals. INQ can engage DET to seek out INF and INT to interpret his 
word. In such a community, it will be very useful to have a concept of good informant that is applicable to INF although INF does not satisfy the epistemic accessibility conditions at issue in the above concept of good informant.

It thus becomes clear how, in sufficiently complex communities, the need for an objective of conception of the good informant arises. Moreover, the above considerations also suggest a particular way in which objectivisation will proceed here: the epistemic accessibility conditionsPK-4 to PK-6-will be relaxed by objectivisation. [Cra90, 87-90]

But what about the other subjective element in the application conditions of the concept of protoknowledge-that INF be as likely to be right as INQ's concerns require, PK-3? There is reason to believe that this condition will also be subject to objectivisation. To see this, consider a community of agents that, in addition to the roles mentioned above, has agents that can employ other agents to obtain information. Let Boss be any agent who fills this role. In communities like this one, it will be useful to have a conception of the good informant that objectivises PK-3 because what matters now are not the concerns of INQ but of Boss. As opposed to the other subjective application conditions governing the concept of protoknowledge, there is reason to believe that objectivisation will tighten rather than relax the reliability condition. After all, neither INQ, nor DET, INT or INF may know just how pressing BOss's concerns are. It will, of course, be useful for the community envisaged to have a conception of the good informant that is applicable even in cases like this one. As Craig [Cra90, 91] rightly points out, in such cases it will be best to prepare for the worst. That is to say, the informant (INF) had better be reliable enough to suit the relevant concerns (of Boss) no matter how exacting these concerns may be. In consequence, there is reason to believe that in the objective conception of the good informant the reliability condition will be tightened: only highly reliable informants will count as good informants objectively construed.

The above considerations show how a need to distinguish between subjective and objective conceptions of the good informant arises in agent communities sufficiently complex to have the roles described. It is this need that motivates the objectivisation of the concept of protoknowledge. Craig [Cra90, 91] argues that the concept of knowledge we have today is what remains after objectivisation. ${ }^{9}$ 


\section{Extending Craig's practical explication to KRI}

At the beginning of the last section, I claimed that Craig's practical explication of the concept of knowledge could be extended to motivate KRI. In what follows I will try to make good this claim. To begin with, notice that our ancestors need not only concepts to evaluate informants, but also concepts to evaluate the linguistic performances of informants. While Craig hypothesises that the former need induced our ancestors to introduce an ancestor of our concept of knowledge, I propose the following parallel hypothesis: The need to evaluate these performances pressurised our ancestors to introduce ancestors of our concepts of felicity and infelicity of informative speech acts, concepts of protofelicity and protoinfelicity of informative speech acts. The function of these concepts is to flag good and bad linguistic performances of informants. ${ }^{10}$

In order to develop the application conditions of the concept of proto(in)felicity, I would like to invite you to focus again on our ancestor community. This time consider a situation in which INQ has put his question to INF, who, in turn, obliges with a response (i.e. performs an informative speech act). Just as Craig developed the application conditions for the concept of protoknowledge by asking what general properties INQ will want INF to have, I will develop the application conditions of the concept of protoinfelicity for informative speech acts by asking in what circumstances INQ will be dissatisfied with INF's linguistic performance. Here are my suggestions. INQ will be dissatisfied with INF's performance if

PI-1 INF has not told INQ the truth; or

PI-2 INF has not managed to perform the speech act in a way that instils belief in INQ; or

PI-3 INF is not (at least) as likely to be right about the question at issue as INQ's concerns require; or

PI-4 the channels of communication aren't open between INF and INQ (for instance because what INF says is unintelligible to INQ).

Notice that these are all properties that, according to Craig, the protoknower does not have. Moreover, it can safely be assumed that INF has the other properties of the protoknower, to wit, detectability (PK-4) and accessibility (PK-6). After all, otherwise INQ would not have put the question to INF in the first place. ${ }^{11}$ In consequence, we may infer that INQ will 
be dissatisfied with INF's performance if INF isn't a protoknower with respect to $P$. (This should not be particularly surprising. After all, it is only plausible that INQ will be dissatisfied with INF's performance if INF performs despite on not being a good informant on the issue.) If this is correct, we get the following condition on protoinfelicity: INF's informative speech act is protoinfelicitous if INF does not protoknow $P$. Or, contrapositively, it is protofelicitous only if INF protoknows $P .{ }^{12}$

Recall that, in Craig's story, in a sufficiently complex community it is useful to have an objective conception of the good informant. In a similar vein, in my story, it is also useful for a sufficiently complex community of agents to have an objective conception of good linguistic performances of informants. To see this, consider once again a situation in which the channels of communication aren't open between INQ and INF (for instance, because INQ and INF speak different languages). Suppose, however, the community to which INF and INQ belong is complex enough to have an interpreter, INT, who can communicate with both INQ and INF. In this situation, INF's linguistic performance isn't a good one in the subjective sense. After all, INF doesn't satisfy PI-4. Suppose, however, that the agents in the community under consideration can collaborate to achieve their goals: INQ can engage INT to interpret INF's words. In such a community, it will be very useful to have a concept of good informant performance that is applicable to INF despite the fact that INF doesn't satisfy PI-4. ${ }^{13}$ The need for an objective conception of good linguistic performances of informants arises.

What's more, just as in Craig's story, these considerations suggest a particular trajectory of objectivisation. After all, it has, once again, become clear that it makes sense that the concept of good informant be applicable to INF even when he does not satisfy this condition. If so, here too, there is reason to believe that the objective conception of the good informant will relax PI- $4 .{ }^{14}$

What about PI-3? An argument parallel to Craig's will suggest that this condition also calls for objectivisation. Take a community of agents that also has a Boss role for agents who can employ other agents to obtain information. Suppose INQ is inquiring into $P$ on behalf of BOss. INF tells INQ that $P$ is the case. In communities like this one, it will be useful to have a conception of good informant performance that objectivises PI-3 because, again, what matters now are not the concerns of INQ but of BOss. Just as in Craig's story, there is reason to believe that objectivisation will tighten rather than relax this condition. After all, neither INQ, nor INF may know just how pressing Boss's concerns are. It will, of course, be useful for the community envisaged to have a conception of good informant 
performance that is applicable even in cases like this one. As we have seen in Craig's discussion, however, in such a situation it is best to prepare for the worst and restrict applicability of the target concept (here: good informant performance) to informants that are reliable enough to suit anyone's concerns.

The above considerations suggest that objectivisation will filter out the subjective elements in the application conditions the concept of protofelicity inherits from the concept of protoknowledge. What's more, I have argued that objectivisation here will proceed along the same lines as objectivisation of the concept of protoknowledge. But now recall that what remains after objectivisation of the concept of protoknowledge in Craig's story is the concept of knowledge. Accordingly, given that Craig's story is correct, there is reason to believe that the objectivised version of the concept of good informant performance will feature the concept of knowledge. (This should also not be particularly surprising. After all, given that the subjective conception of good linguistic performance is applicable only to good informants in the subjective sense (i.e. protoknowers), it is only to be expected that its objective cousin should be applicable only to good informants in the objective sense (i.e., if Craig is right, knowers).) ${ }^{15}$

The considerations provided in this section thus suggest that Craig's practical explication of the concept of knowledge can be extended to argue that the concept of knowledge will feature in the felicity conditions of informative speech acts. More specifically, given that protofelicity requires protoknowledge and given that objectivisation filters out the subjective elements the concept of protofelicity inherits from the concept of protoknowledge in the way indicated, the concept of knowledge will figure in the felicity conditions of informative speech acts in the following way: An informant's speech act is felicitous only if the informant knows its content. If all this is correct, we can easily derive KRI from the additional, uncontroversial premise that one ought to perform only felicitous speech acts. ${ }^{16}$

\section{Problem cases}

With the practical explication of the knowledge rule in play I will now discuss a number of problem cases that can be found in the literature. ${ }^{17}$ Matthew Weiner [Wei05] adduces a first set of cases that he takes to disprove the knowledge rule of assertion. Here is one: Captain Aubrey and Lieutenant Pullings have been watching the French ships manoeuvre all day. At some point in the afternoon, Aubrey says: "The French will wait until nightfall to attack." Intuitively, Aubrey's prediction is per- 
fectly in order. At the same time, argues Weiner, Aubrey's prediction is an assertion. Why? Because (i) a crucial feature of assertion is that "the default use of declarative sentences is to make assertions" [Wei05, 288] and (ii) "assertion is a broad category, which will not be restricted to acts that are based ... on certain kinds of evidence." [Wei05, 288] In view of these facts about assertion Weiner proposes a "conception of assertion as a genus that comprises species such as reports, predictions, arguments, reminders, and speculations." [Wei05, 229] Since prediction is a species of assertion, Aubrey's speech act qualifies as an assertion. So, Aubrey performs an assertion that is perfectly in order. At the same time, it is clear that Aubrey does not know the content of his speech act. His evidence (watching the French manoeuvre) is not strong enough to give him knowledge.

Fortunately, Weiner's case does not pose a genuine threat to the knowledge rule as defended here. Recall that the aim of my argument is to show that the knowledge rule governs the class of informative speech acts. Arguably, however, predictions do not fall within this class. To see this, recall that informatives were characterised as speech acts the point of which is to engender outright belief in the hearer, that have a word-toworld direction of fit and which are expressive of outright belief. While predictions have word-to-world direction of fit, they are not expressive of outright belief and, correlatively, their point and purpose does not consist in the engendering of outright belief in the audience. Consider someone who predicts that it will rain tomorrow. Sure enough, in making the prediction this person expresses a certain degree of confidence in the proposition at issue, one that exceeds his degree of confidence in its negation. However, he does not express outright belief in that proposition. ${ }^{18}$ If he were expressing outright belief, he would no longer be predicting. What comes to light, then, is that predictions are not informative speech acts. Hence, even if Weiner is right about Aubrey's prediction being perfectly in order and about prediction being a species of assertion, his case does not refute the thesis, defended here, that informative speech acts are governed by the knowledge rule. It follows that assertion does not fall within the class of informatives. However, that is perfectly consistent with the aim of this paper. ${ }^{19}$

The next set of cases I will discuss can be found in a recent paper by Ishani Maitra and Brian Weatherson [MW10] who claim that it is sometimes permissible to assert a proposition of the form " $\phi$ is the thing to do" even though one does not know this to be the case. In one of their cases, the leaders of a country evaluate the known evidence bearing on the question as to whether to go to war with another country and come 
to the conclusion that it is. While they have reached the right conclusion, they do not know it to be true, as the evidence only slightly favours going to war. Had the evidence been minimally different, which it might easily have been, it would not have done so. ${ }^{20}$ Against this background, Maitra and Weatherson envisage a scenario in which the country's Prime Minister delivers a speech in the House of Commons in which he explains the reasons bearing on the question under consideration. How should the Prime Minister conclude his speech? Maitra and Weatherson offer two alternatives:

End-1 "So, the thing to do in the circumstances is to go to war."[MW10, 2]

This, however, would be in violation of the knowledge rule. In order to assert within the bounds of the knowledge rule, Maitra and Weatherson claim, the Prime Minister will have to say something like the following:

End-2 "These are all strong reasons for going to war, but I can't say whether they make going to war the thing to do. Nevertheless, I'm starting the war tomorrow." [MW10, 2]

I agree with Maitra and Weatherson's observation that End-1 is a better way to end the speech than End-2. It is fairly clear, however, that this isn't enough to refute the knowledge rule. In order to fill the gap, Maitra and Weatherson make the following additional claim: "End-2 is a better way to end the speech than anything else we can think of that does not violate the knowledge rule." [MW10, 2] And here is where problems arise.

To begin with, it is not even clear that End-2 does not violate the knowledge rule. It will do so only if the Prime Minister knows that he does not know that going to war is the thing to do. And it is not obvious that he does know this. More to the point, however, there is an alternative available to the defender of the knowledge rule, viz.

End-3 "The available evidence suggests that the thing to do is to go to war."

This is something that the Prime Minister can know and hence something that, in the above case, we may assume he does know. For even if it is granted that the Prime Minister's evidence is not robust enough to enable him to know that going to war is the thing to do because he might easily have had slightly different evidence that would not have favoured going to war, the content of End-3 concerns what the evidence he actually has 
indicates. And, surely, the Prime Minister can know what his evidence indicates even if different evidence would have indicated something else.

The question remains whether it is better to conclude the speech by an assertion of End-1 or by an assertion of End-3? The correct answer, it seems to me, is that it does not matter. ${ }^{21}$ The Prime Minister could have ended his speech either way. It is crucial to note that the reason why it does not matter is that, in the context of the speech, the Prime Minister's assertion of End-1, conveys no more than the claim at issue in End-3. To see this, suppose someone were to criticise the Prime Minister for asserting End-1 despite not knowing its content. The obvious response for the Prime Minister here is that the criticism considers the assertion out of the context in which it was made. In context, the prime minister might add, it was clear that what was meant by the assertion is End-3. Notice, furthermore, that if the Prime Minister were to assert End- 1 out of a context in which the relevant reasons are tabled, his assertion would be inappropriate. Here the Prime Minister could permissibly assert only the weaker End-3. If this is correct, then there is excellent reason to believe that Maitra and Weatherson's case is not a counterexample to the knowledge rule either.

The last set of counterexamples against the knowledge rule I will consider here is due to Jennifer Lackey [Lac08]. In these cases speakers "selflessly" perform informative speech acts. ${ }^{22}$ In one of her cases, a teacher believes in creationism but teaches her students propositions she knows presuppose the truth of evolutionary theory and which therefore she does not believe. She does this because she is aware that the evidence best supports evolutionary theory and considers it her duty to teach what is best supported by the evidence.

More generally speaking, Lackey argues that her cases work against the knowledge rule in virtue of possessing the following three features:

[F]irst, a subject, for purely non-epistemic reasons, does not believe (and hence does not know) that $P$; second, despite this lack of belief, the subject is aware that $P$ is very well-supported by all of the available evidence; and, third, because of this, the subject [informs her interlocutor] that $P$ without believing and, hence without knowing that $P$. [Lac08, 112]

To begin with, notice that Lackey's cases pose a problem not just for KRI but also for the Craigian approach to epistemology in general. After all, the agents in Lackey's cases are good informants even in the objective sense: not only do they tell their interlocutors truths, they are also highly convincing as well as highly reliable. This would be bad news 
for the Craigian, because the cases would constitute exactly the kind of mismatch in the intuitive extension that, according to Craig [Cra90, 2], would disconfirm the view. It is thus of considerable importance for the Craigian to provide a satisfactory account of these cases. ${ }^{23}$

Fortunately, however, there are various ways of achieving this. One strategy I have already discussed elsewhere [Aut09a] is to maintain that the agents have the relevant beliefs after all. The Craigian can get this result for instance by adopting an evidentialist account of belief à la Jonathan Adler according to which one must believe $P$ provided "in full awareness one regards one's evidence or reasons as adequate to the truth of $P$." [Ad103, 32] Since one of the structural features, that, according to Lackey, make the cases work is that the agents are fully aware that the evidence makes a convincing case for the relevant propositions, by Adler's account of belief they must also believe them to be true. That is to say, however, that if Adler is right, it is impossible for the agents in Lackey's cases not to believe the relevant propositions. And since all that prevents Lackey's agents from knowing is their alleged lack of belief, it turns out that they know after all. This, of course, will defuse the threat Lackey's cases pose to both the knowledge rule and the Craigian approach to epistemology in general.

It may be noteworthy that the Craigian does not have to rely on external aids, such as Adler's account of belief, to deal with this Lackey's cases. Rather, the Craigian framework already provides the resources to give what to my mind is a rather elegant analysis of them. To see this, notice, first that Craig explicitly contrasts his practical explication of the concept of knowledge with the traditional project of a reductive analysis. One of the professed benefits of the Craigian approach is that it can allow that certain conditions are not strictly speaking necessary for the concept of knowledge, whilst still assigning them a central role in our understanding of it. This is exactly the strategy that Craig pursues for the belief condition for knowledge. Recall that one of the central properties of the good informant is:

PK-2 if INF tells INQ that $P$, INQ shall thereupon believe that $P$

In the Craigian story, belief plays a central role in our understanding of the concept of knowledge because, typically, if INF does not himself believe what he says he won't perform his speech act with enough confidence to induce belief in INQ. [Cra90, 13] For that reason, typically, a good informant will also be one who believes what he says. At the same time, Craig is very clear that belief is not an essential property of good informants. Other properties can fill the role typically played by belief. As 
a result, the Craigian approach leaves room for the possibility of knowledge without belief. And, arguably, the agents in Lackey's cases possess a number of such properties so that, by the lights of the Craigian, the cases lend themselves to analysis as cases of knowledge without belief.

To begin with, the agents in Lackey's cases are all aware that their lack of belief in the relevant proposition is based on purely non-epistemic grounds and that the available evidence supports belief. In other words, the agents are aware that the relevant propositions are well supported and that their doxastic states are somewhat peculiar. For that reason they are especially well positioned to perform their informative speech act confidently even when lacking the relevant belief. Furthermore, as Craig points out, even when lacking a belief that $P$, one may satisfy PK-2 provided one possesses "a property that correlates well-as we believewith telling the truth about P." [Cra90, 13] The agents in Lackey's cases all possess such a property. In the above example, the speaker is a biology teacher and thus possesses a property that is widely believed to correlate well with telling the truth about matters biological. ${ }^{24,25}$ It comes to light, then, that the agents in Lackey's cases possess a couple of properties suited (especially when conjoined) to fill the role that, by the light of the Craigian, is typically played by belief. As a result, the Craigian can analyse Lackey's cases as cases of knowledge without belief (without jeopardising the centrality of belief to our understanding of the concept of knowledge). ${ }^{26}$ Again, the cases fail to constitute an insurmountable problem to the Craigian approach to epistemology or to the knowledge rule of informative speech acts. ${ }^{27}$

\section{Conclusion}

In conclusion, in this paper I have extended Craig's practical explication of the concept of knowledge to motivate KRI. While in Craig's story, the concept of knowledge is what remains after objectivisation of the concept of good informant, in my story, the concept of felicity is what remains after objectivisation of the concept of good linguistic performances of informants. Crucially, I have argued that if Craig's story about the concept of knowledge is correct, there is also reason to believe that the objective conception of good linguistic performances of informants will feature the concept of knowledge: such performances are felicitous only if the performer knows its content. Finally, I have discussed a number of problem cases for the knowledge rule, viz. (a) cases of felicitous but unknown predictions, (b) cases in which the subject felicitously asserts/tells someone that something is the thing to do, whilst, apparently not knowing it and 
(c) cases of felicitous informative speech acts in which the subject lacks the relevant belief. It turned out that none of these problem cases refute the knowledge rule of informative speech acts as defended in this paper.

\section{References}

[Ad103] Adler, J. 2003. Belief's Own Ethics. Oxford: OUP.

[Aut07] Author 2007.

[Aut09a] Author 2009a.

[Aut09b] Author 2009b.

[BH79] Bach, K. and Harnish, R.M. 1979. Linguistic Communication and Speech Acts. Cambridge, Mass.: MIT Press.

[Cra90] Craig, E. 1990. Knowledge and the State of Nature. An Essay in Conceptual Synthesis. Oxford: Clarendon.

[Fri08] Fricker, M. 2008. 'Scepticism and the Genealogy of Knowledge.' Philosophical Papers 37: 27-50.

[Gre07] Greco, J. 2007. 'The Purpose of Knowledge and the Nature of Ability.' Philosophical Issues 17: 57-69.

[Gre08] Greco, J. 2008. 'What's Wrong with Contextualism?' The Philosophical Quarterly 58: 416-35.

[Kus09] Kusch, M. 2009. 'Testimony and the Value of Knowledge.' Haddock, A., Millar, A. and Pritchard, D. eds. Epistemic Value. Oxford: OUP.

[Lac08] Lackey, J. 2008. Learning from Words. Testimony as a Source of Knowledge. Oxford: OUP.

[MW10] Maitra, I. and Weatherson, B. 2010. 'Assertion, Knowledge, and Action.' Manuscript. http://brian. weatherson.org/AKA . pdf. Feb 2010.

[Pri05] Pritchard, D.H. 2005. Epistemic Luck. Oxford: OUP.

[Pri09] Pritchard, D.H. 2009. Knowledge. Basingstoke: Palgrave Macmillan. 
[Pri10] Pritchard, D.H. 2010. 'Anti-Luck Virtue Epistemology.' Manuscript.

[Sea69] Searle, J. 1969. Speech Acts: An Essay in the Philosophy of Language. Cambridge: CUP.

[Sea76] Searle, J. 1976. 'A Classification of Illocutionary Acts.' Language in Society 5: 1-23.

[Sha03] Shah, N. 2003. 'How Truth Governs Belief.' The Philosophical Review 112: 447-82.

[Slo79] Slote, M. 1979. 'Assertion and Belief.' Dancy, J. ed. Papers on Language and Logic. Keele: Keele University Press.

[Sos02] Sosa, E. 2002. 'Tracking, Competence, and Knowledge.' Moser, P. ed. The Oxford Handbook of Epistemology. Oxford: OUP.

[Ung75] Unger, P. 1975. Ignorance: A Case for Scepticism. Oxford: Clarendon.

[Vel00] Velleman, D. 2000. 'On the Aim of Belief.' The Possibility of Practical Reasoning. Oxford: OUP.

[Wed02] Wedgwood, R. 2002. 'The Aim of Belief.' Philosophical Perspectives 16: 267-97.

[Wei05] Weiner, M. 2005. 'Must We Know What We Say?' The Philosophical Review 114: 227-51.

[Wi196] Williamson, T. 1996. 'Knowing and Asserting.' The Philosophical Review 105: 489-523.

[Wil00] Williamson T. 2000. Knowledge and Its Limits. Oxford: OUP.

\section{Notes}

${ }^{1}$ Notice that the "must" here-as well as the "must" at issue in the knowledge rule of informative speech acts (see below) - does not express an all-things-considered norm. Rather it expresses a norm of appropriateness for assertion (informative speech acts), more specifically, an epistemic such norm.

2 The most comprehensive case for KRA to date can be found in [Wil96, Wil00]. Earlier defences include [Ung75] and [Slo79].

${ }^{3}$ For stylistic reasons, in what follows I will allow myself to drop the predicates "outright" and "true" and just talk about the engendering, expression etc. of belief. Notice also that "true" here may well be redundant-for instance, if belief constitutively 
aims at truth in the sense envisaged, among others, by Nishi Shah [e.g. Sha03], David Velleman [e.g. Vel00] and Ralph Wedgwood [Wed02].

${ }^{4}$ I am adopting Searle's [Sea76] manner of classifying speech acts here which accords greatest importance to a speech act's point and purpose, its direction of fit and the attitude expressed in it. (For an alternative see [BH79] which proposes to classify speech acts exclusively in terms of expressed attitude.) It may be worth noting that to express an attitude in the sense envisaged by Searle here is not to possess the attitude: one can express an attitude one does not possess. This is clear once one considers how Searle explains what it is to express an attitude, viz. in terms of the sincerity condition of the act:

Wherever there is a psychological state specified in the sincerity condition, the performance of the act counts as an expression of that psychological state. [Sea69, 65, emphasis in original]

Since it is possible to perform at least certain speech acts (among them informatives) insincerely, i.e. whilst not possessing the attitude at issue in the sincerity condition, it must also be possible to express an attitude one does not possess. (Bach and Harnish BH79] propose an alternative account of what it is to express an attitude, which also countenances the distinction between possessing and expressing an attitude.)

${ }^{5}$ The knowledgeable reader will wonder how this idea fits with Williamson's [e.g. Wil00, ch.11] knowledge account of assertion. I describe a couple of ways of reconciling KRI with (at least the spirit of) Williamson's knowledge account of assertion in [Aut07].

${ }^{6}$ Is assertion an informative speech act? Given that the above general characterisation of informatives is correct, the answer to this question will ultimately depend on whether assertion meets the criteria stated there. While it may initially seem plausible that, given the above characterisation, assertion does qualify as an informative, it will become clear in due course that there may also be reason to think that it doesn't. I do not mean to settle this question within the scope of this paper. Of course, if it turns out that assertion does not fall within the class of informatives, the present paper does not succeed in providing a defence of the knowledge rule of assertion. Regarding assertion, then, I will, for present purposes, rest content with aiming to establish the following conditional claim: if assertion is an informative speech act, then it is governed by the knowledge rule.

${ }^{7}$ Notice that I will not be defending the Craigian approach to epistemology here. Rather, I will be assuming that it is viable. It may be worth pointing out that I am not the only one who draws on Craig's work in this way. On the contrary, it is fair to say that there has been a trend in recent epistemology to do just this. Examples include John Greco [e.g. Gre07: Gre08], Duncan Pritchard [e.g. Pri09; Pri10], Martin Kusch [Kus09] and Miranda Fricker [Fri08]. Those who are worried about this assumption are invited to conditionalise my conclusions in the obvious ways.

${ }^{8}$ The scare quotes here are to indicate that the term is not meant not refer to anyone who ever inhabited this planet. In order to maximise readability, in what follows, I will omit the scare quotes.

${ }^{9}$ Notice that this serves to explain away the difference between the concept of protoknowledge and the concept of knowledge mentioned above. Luigi does not satisfy PK-5 and therefore doesn't qualify as a protoknower. However, objectivisation relaxes this condition. Given that, by Craig's lights, the concept of knowledge is what remains of the concept of protoknowledge after objectivisation, Craig's account yields the intuitive result that Luigi qualifies as a knower. 
10 The thesis that the need to evaluate linguistic performances of informants pressurised our ancestors to introduce ancestors of our concepts of protofelicity and protoinfelicity (ancestors of our practice of informative speech acts) may well generalise to other speech acts. While it seems plausible to me that it should, for present purposes, the weaker thesis, the one limited to informants' speech acts in the situations under consideration, is sufficient.

${ }^{11}$ Notice also that in situations in which it cannot safely be assumed that INF has these properties, INQ will be dissatisfied if INF doesn't have them. For instance, were INF to volunteer the information (without thereby making himself detectable as likely to be right on the issue), INQ would remain dissatisfied with INF's performance. Similarly, if INF were to perform the speech act at a time or place inaccessible to INQ.

${ }^{12}$ Are the application conditions of the concepts of protofelicity of informative speech acts and protoknowledge identical? There is some reason to think that if they are indeed identical, there are problems for sympathisers with Craig's approach to epistemology on the horizon. After all, a protofelicitous informative speech act will be one that makes a relevant contribution to the conversation, is not overly informative etc. The problem arising for the Craigian here is that, plausibly, if these conditions go into the application conditions of the concept of protoknowledge, they will also survive objectivisation. After all, a good informant in the objective sense is still one who makes a relevant contribution (at least if he makes any contribution at all), is not overly informative etc. At the same time, there is nothing in the intuitive intension of the concept of knowledge we are familiar with corresponding to these conditions. As Craig himself concedes [Cra90, 2], such differences in intuitive intension between the objectivised concept of good informant and our contemporary concept of knowledge mean trouble for his account. The Craigian may thus be better advised to distinguish between properties specific to good informants, which go into the application conditions of the concept of good informant and properties of good linguistic performers in general, which do not.

Suppose for a moment, however, that the application conditions of the two concepts were indeed identical. Bracketing the above problems for the Craigian, in and of itself, this would not be too bad. If anything, it would provide support for a close conceptual link between the concepts of knowledge and of informative speech act. What would be bad, however, is if the concepts of felicity of informative speech acts and of knowledge turned out to have identical application conditions. After all, it is quite obvious that they don't. Fortunately, there is good reason to think that, by the lights of the Craigian, these two concepts come apart even if the concepts of protofelicity and protoknowledge do not. I will get back to this point in due course.

13 Similarly for situations in which INF performs despite not being accessible to INQ or detectable by INQ as sufficiently likely to be right on the issue. It will be useful for the concept of good informant performance to be applicable to INF's performance even in these situations if, for instance, the community is complex enough to also have detectives and reporters.

${ }^{14}$ And again, similarly, for the detectability and accessibility conditions.

${ }^{15}$ In n.12 I considered the possibility that the application conditions of the concepts of protofelicity of informative speech acts and of protoknowledge are identical. I argued that, while this may still be acceptable, the Craigian would be in trouble if it turned out that, by his lights, the application conditions of the concepts of felicity of informative speech acts and of knowledge are identical. I will now provide reason to think that, even if the application conditions of the concepts of protofelicity and protoknowledge are identical, by the lights of the Craigian, the conditions governing the application of 
the concepts of felicity and knowledge come apart. To see this, consider the following application condition of the concept of protofelicity (and, given the assumption of identity, of the concept of protoknowledge):

PF INF does not commit a (linguistic) performance error.

To see why the application conditions for the concepts of felicity and of knowledge come apart, notice, first, that there is reason to think that PF, understood as an application condition of the concept of good informant, will be subject to objectivisation-at least in a community of sufficiently sophisticated agents. Thus consider a community of agents who can store information in memory and retrieve it on a number of different occasions. It makes sense to have a concept of good informant that applies to agents who, whilst being generally highly reliable linguistic performers, are susceptible to occasional performance errors. As a result, there is reason to think that objectivisation of the concept of good informant will relax PF: someone can be a good informant in the objective sense even when he occasionally commits performance errors. However, there is no reason to think that felicity, even in the objectivised form that we are familiar with today, is compatible with errors in linguistic performance in the same way. Generally speaking, when a speaker commits an error in linguistic performance, his speech act will as a result be infelicitous (even though performance errors are rare for the speaker). Thus, even if the application conditions of the concept of protofelicity and of protoknowledge are identical, the concepts of felicity of informative speech acts and knowledge differ.

${ }^{16}$ It may be contentious, to say the least, to claim that one ought, all things considered, to perform only felicitous speech acts. However, recall that the norm at issue in KRI is a norm for appropriateness of speech acts (see n.1). As a result, the derivation of KRI goes through provided "ought" here is expressive of such a norm. Once this point is understood, it is clear that the above premise is indeed uncontroversial.

${ }^{17}$ I will not discuss informative speech acts of subjects who have reasonable beliefs that fall short of knowledge or of subjects who perform informative speech acts because, for instance, the urgency of the situation requires it. In my view, these cases have already received satisfactory treatment in [Wil00]. Instead, I will restrict my focus to cases that have been claimed to escape Williamson-style treatment.

${ }^{18}$ This is supported by Searle's account according to which the attitude expressed in performing a speech act is the attitude specified in the speech act's sincerity condition (see n.4 above). Predictions can be sincere even though one does not outright believe what one predicts. For instance, one's prediction that it will rain or that Thunderbolt will win the upcoming horse race can be sincere even though one does not have the corresponding outright beliefs. Hence, by Searle's account, outright belief isn't the attitude expressed in predictions.

Notice, furthermore, that it does not follow from the fact that predictions do not express outright belief that the speaker does not possess the relevant outright belief. People may, as a matter of psychological fact, possess all sorts of attitudes that they do not express in the speech acts they perform.

${ }^{19}$ Recall that I argued in n.6 that my argument will provide support for the knowledge rule of assertion only provided that assertion falls within the class of informatives.

${ }^{20}$ Maitra and Weatherson argue that this suffices for lack of knowledge because knowledge requires safety, i.e. avoidance of error at nearby possible worlds [MW10, section 3]. It is noteworthy, however, that most defenders of safety-notably Pritchard [e.g. Pri05], Sosa [e.g. Sos02] and, perhaps not obviously but arguably [see Aut09b], Williamson [Wil00]-require that the grounds for belief be held fixed in the evaluation 
for safety. Since Maitra and Weatherson's cases trade on the subjects' having slightly different evidence (i.e. grounds for belief) at nearby worlds, it is far from clear that these cases constitute cases of unsafe belief. One move the defender of the knowledge rule can make then is to argue that the subjects in these case do know and explain away any residual intuition that they don't in terms of a confusion between ignorance and knowledge that was almost not had. For the purposes of the present argument, however, I will grant Maitra and Weatherson at least that the agents in their cases do not know the relevant propositions.

${ }^{21} \mathrm{Or}$, in any case, the considerations that might still favour an assertion of End-1-for instance, its length or its greater persuasive power-are not epistemic and thus pose no problem for the defender of the knowledge rule.

${ }^{22}$ Lackey's official target is the knowledge rule of assertion. However, it is not hard to see that if her cases work against the knowledge rule of assertion, they will also work against the knowledge rule of informative speech acts. In fact, the relevant speech acts in Lackey's cases are arguably all informatives. Accordingly, it should not be controversial that I construe Lackey's cases as targeting KRI.

${ }^{23}$ Relatedly, we must not expect Lackey's cases to demonstrate that the Craigian approach to epistemology fails to motivate KRI. Instead, the two theses will stand or fall together here.

${ }^{24}$ Her other cases feature, respectively, a juror making a claim about the innocence of the defendant in one of his court cases and doctor telling a patient about a certain connection between vaccines and autism. Here again, the agents possess properties (being a juror in one case and being a doctor in the other) that are widely believed to correlate well with telling the truth about the relevant issues.

${ }^{25}$ Notice that the two kinds of property that may fill the roll typically filled by belief are related. For instance, the biology teacher's awareness of her evidential edge over of most the general public in matters biological may boost her confidence when speaking on these matters. The same goes for the other two cases.

${ }^{26}$ After all, recall that what explains this centrality is the thought that PK-2 is typically satisfied in virtue of the agents' believing what they tell their interlocutors. This thought is not called into doubt by the present analysis of these cases.

${ }^{27}$ One final objection: I have assumed, with Searle, that the attitude expressed in a speech act is its sincerity condition (n.4). Moreover, I have also taken it that the attitude expressed in informative speech acts is belief. It follows from these assumptions that belief is the sincerity condition of informative speech acts. If Lackey's cases are analysed as cases of knowledge without belief, it follows that the relevant speech acts are not sincere. This is a problem if one also wants to hold that only sincere speech acts can be felicitous. After all, the informative speech acts in Lackey's cases are assumed to be felicitous.

Consider the question whether the speech acts in Lackey's cases are sincere. For what it's worth, my intuitions do not suggest a clear answer here. Fortunately, the objection can be dealt with no matter whether the speech acts turn out to be sincere or insincere. To see this, suppose first that they aren't sincere. In that case, the objection will affect, in the first instance, not my account of Lackey's cases but the force of the cases as counterexamples to KRI. If only sincere speech acts can be felicitous, then Lackey's cases are not cases of felicitous speech acts that violate the knowledge rule. Hence, they don't constitute counterexamples to the knowledge rule. (Lackey discusses a similar objection to her cases. In her version of the objection, the charge is that the speakers are lying and that, therefore, they violate a norm of assertion. [Lac08, 
115] She responds to the objection by drawing a distinction between two senses of lying: a lie in the first sense is an assertion of what one does not believe, while a lie in the second sense is an assertion of what one does not believe that is also made with the intention to deliberately deceive. She claims that only the second kind of lie is necessarily in violation of a norm of the speech act performed. [Lac08, 117] Applied to the present version of the objection, the suggestion would be that only certain kinds of insincerity, the ones that include an intention to deliberately deceive, will necessarily lead to infelicity, while, in certain restricted cases, it is possible to felicitously perform speech acts that aren't sincere. Of course, if, in order to get her cases off the ground, Lackey already assumes the possibility of felicitous but insincere speech acts, it shouldn't count against my account of the cases if I make this assumption as well.) Suppose next that the speech acts Lackey's cases are sincere. Of course, in that case the objection does not even get off the ground. However, the question arises what the sincerity condition of informative speech acts is and whether it continues to support my analysis of Weiner's cases as cases in which the relevant speech acts are not informatives (see n. 18). For present purposes, I will restrict my discussion to what appears to me to be the most promising alternative proposal here: an informative speech act that $P$ is sincere if the speaker believes that the evidence warrants outright believing that $P$. This proposal will render the speech acts in Lackey's cases sincere. Notice also that it still supports my analysis of Weiner's cases. After all, one can sincerely predict that it will rain tomorrow, that Thunderbolt will win the upcoming race etc. even if one doesn't believe that the evidence warrants the corresponding outright beliefs. Hence the attitude expressed in predictions is not belief that the evidence warrants outright belief. Hence predictions aren't informatives speech acts. 